\title{
A RARE CASE OF COMPLETE HEART BLOCK
}

\author{
BY
}

\section{KEMAL SARACOGLU}

From the International Clinic, Constantinople

Received October 23, 1943.

Complete heart block is not rare, but the case to be described has some very unusual features. A woman, aged 50 years, working as a doctor's servant, first came to us in March, 1937, for intestinal worms. She also complained of anxiety and dyspnœa, but at the first consultation nothing was mentioned about her real illness.

On 23/2/38 she came again for her heart disease. She complained of anxiety, heartache, and dyspnœa. Her illness had begun three months before and she stated that she suffered more during the night than the day. She was married and had borne five children, who had all died during the first days of their life. Her husband had died after a short illness, but she did not know the name of his disease.

At the examination of the patient we observed the following: her face was pale and her

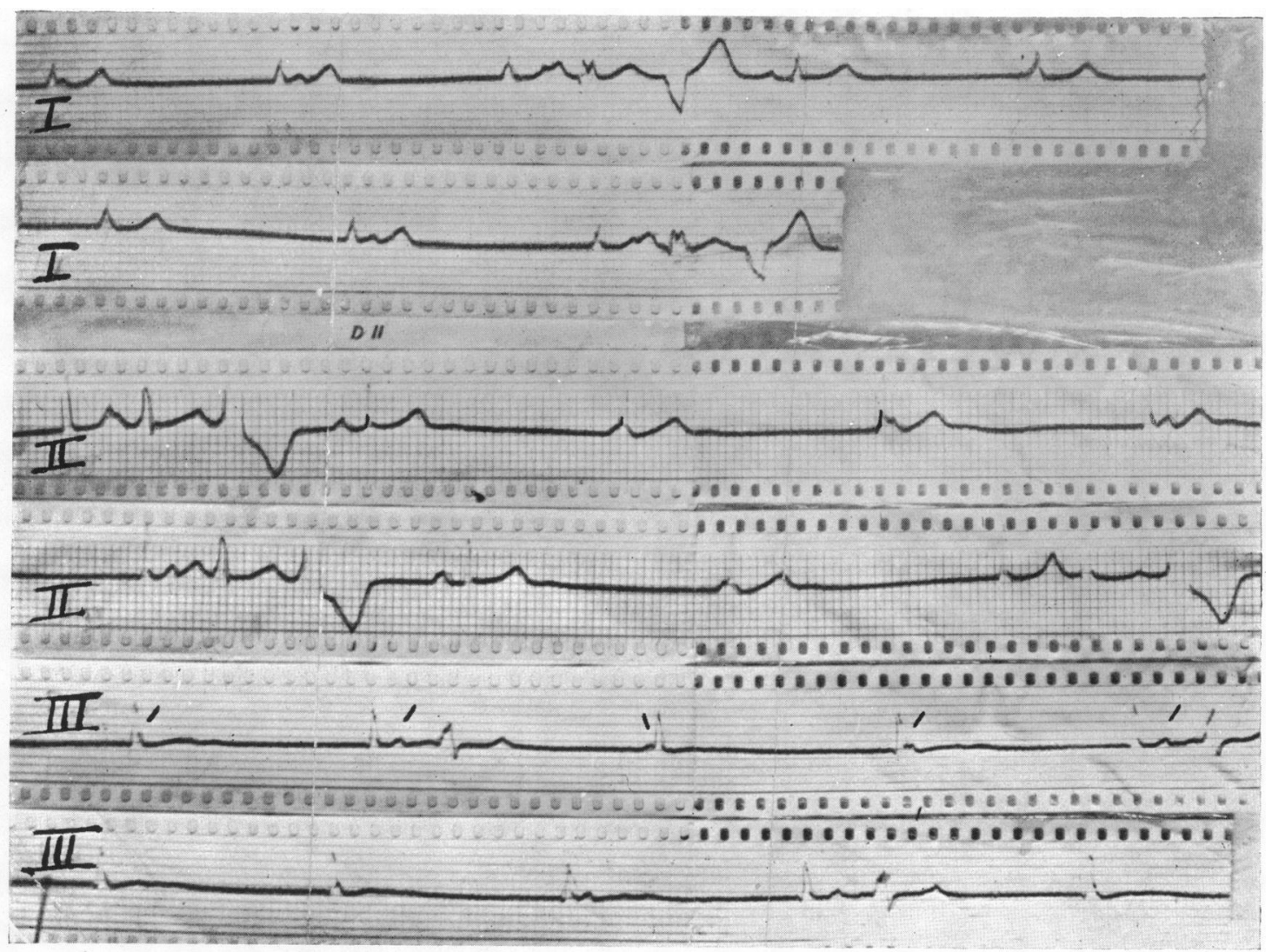

FIG. 1.-Electrocardiograms showing complete heart block with frequent ventricular extrasystoles, and the ventricular rate (about 40 ) slightly faster than the auricular rate (about 39 a minute). 
dyspnœa increased during exertion. Her heart beats were irregular on account of extrasystoles. Her pulse rate was 40 . This bradycardia was a serious symptom. On examining her lungs we found some dry rales. Her blood pressure was 200/100 with the Vaquez apparatus. There was nothing important in her other organs. The urine was normal. The Wassermann and Kahn reactions were negative.

The most important findings were in the cardiogram (Fig. 1). Extrasystoles appeared after four or five ventricular beats. The number of the regular beats were 40 a minute. There was an important bradycardia caused by complete heart block, because the auricular beats were independent of the ventricular beats. One point attracted our special attention, namely, that the number of the auricular beats were 39 and the ventricular beats 40 a minute. Indeed, in complete heart block it should be the contrary, with the auricular beats from about 60 to 80 and the ventricular beats about 35 a minute. So a complete heart block was combined with slowness of the auricular rate. What could be the cause of this slowness? The following diseases must be considered: cerebral tumour, meningitis, cerebral commotion, cholæmia, digitalis intoxication, typhoid fever, hypothyroidism, vagotonia, and last, coronary sclerosis. In our case only two things seemed to be possible: (1) vagotonia, or (2) the destruction or degeneration of the Keith-Flack node.

In order to discard the first possibility we injected atropine and adrenaline and afterwards we took a new cardiogram (Fig. 2). These medicaments did not change the slowness of the

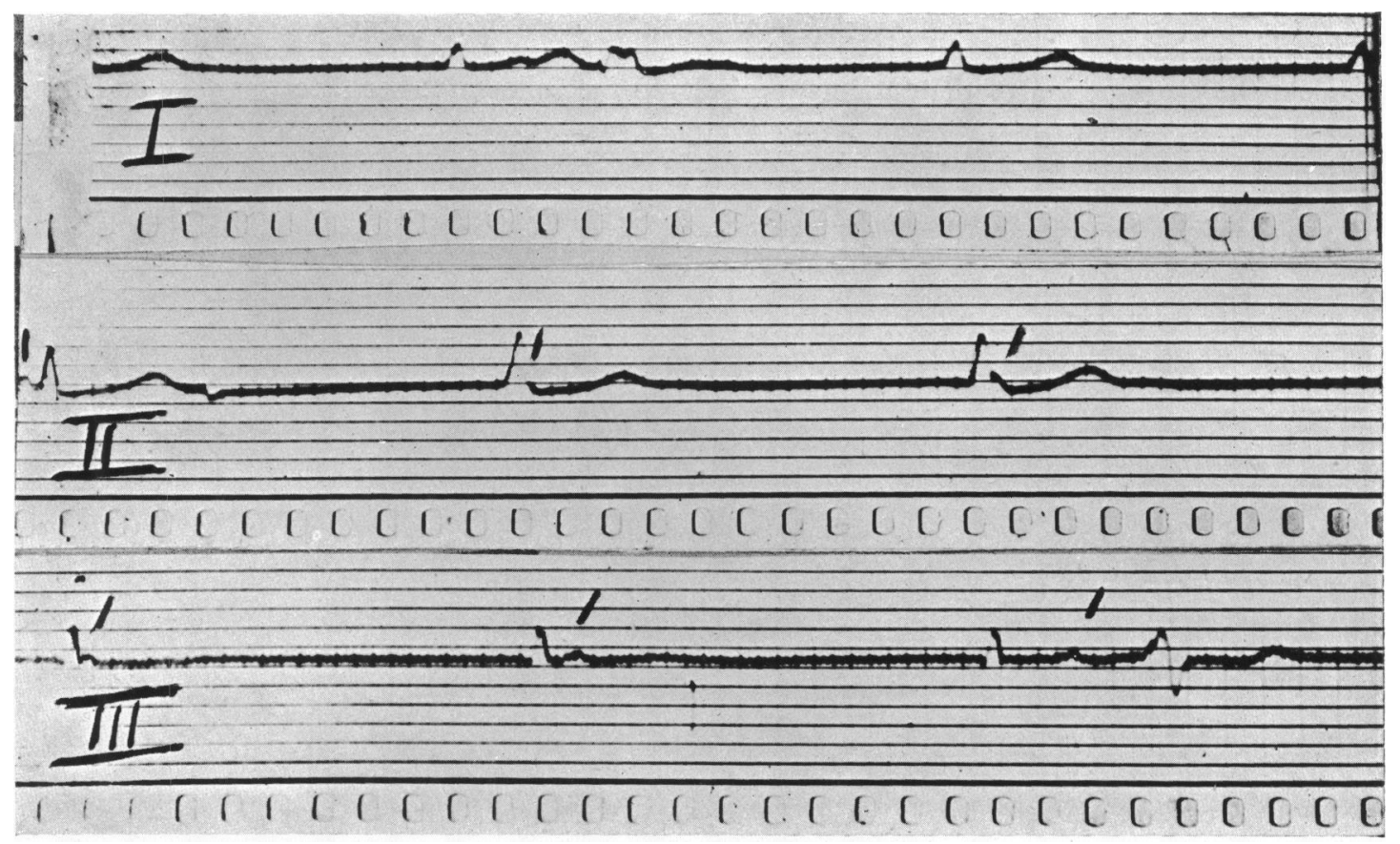

FIG. 2.-Electrocardiograms after the injection of atropine and adrenaline, showing no significant change in the slow auricular rate.

auricular beats. Therefore we decided that it was not the result of vagotonia, but of a coronary sclerosis. The coronary arteries being unable to vascularize the Keith-Flack node, the excitation produced was under the normal rate.

This form of complete heart block with slow auricular beats is very rare. Some parts of the records taken with Siemens apparatus appeared somewhat like fibrillation or nodal rhythm, but the figure as a whole show that it was an example of complete heart block.

Further records were not possible because the patient died. At the section of the body we found a diffuse myocarditis. 


\section{SUMMARY}

A case of complete heart block with a rare degree of auricular bradycardia is described. The ventricular rate was 40 and the auricular rate 39 a minute.

As the auricular rate was not influenced by atropine or adrenaline it was thought to be due to coronary disease and not to increased vagal tone. 